\title{
Microvesicles and exosomes as vehicles between protozoan and host cell communication
}

\author{
Poliana Deolindo ${ }^{1}$, Ingrid Evans-0sses ${ }^{1}$ and Marcel Ivan Ramirez ${ }^{2}$
}

Laboratorio de Biologia Molecular de Parasitas e Vetores, Instituto Oswaldo Cruz-Fiocruz, Rio de Janeiro, 21040-900, Brazil

\begin{abstract}
Cells release extracellular vesicles in response to external factors or in a physiological way. Microvesicles and exosomes originate in cells in different ways and, depending on their contents, may have multiple biological effects on other cells and the environment. The host cell-parasite relationship could be changed dramatically by the plasticity of a new type of communication through extracellular vesicles. In the present paper, we discuss how protozoans use this new resource to evade the immune system and establish infection.
\end{abstract}

\section{Introduction}

Extracellular vesicles were first reported many years ago [1]. In the subsequent decades, diverse extracellular vesicles released from different cells were described. Ectosomes, plasma membrane MVs (microvesicles), exosomes, microparticles, apotoptotic bodies and other terms describe vesicles secreted from cells in different physiological states or under various stimuli.

Efforts have been made by the scientific community working with extracellular vesicles to define concepts and methods to regulate experimental approaches in this area of research. A remarkable meeting organized by the International Society for Extracellular Vesicles in Gothenburg (17-21 April 2012) discussed the biological functions and roles of extracellular vesicles and reviewed methods and protocols to separate, purify and characterize vesicles. Although some groups continue to use the nomenclature with specific names for their vesicles under study, there is a consensus to classify them into three groups on the basis of size: exosomes $(<100 \mathrm{~nm}), \mathrm{MVs}$ $(100 \mathrm{~nm}-1 \mu \mathrm{m})$ and apoptotic bodies $(>2 \mu \mathrm{m})$.

Evidence from groups working on extracellular vesicles demonstrated that, technically and conceptually, there is no discrepancy between the origin and biological relevance of apoptotic bodies. However, the biogenesis, transport, content and biological effect of exosomes and MVs depend on the cells involved and the stimuli that cause the release of extracellular vesicles. The concepts of exosomes and MVs are often confused or used interchangeably.

The first part of the present review characterizes exosomes and MVs and highlights differences in biogenesis, which seem to be independent pathways or are activated by different inductors. We summarize the involvement of exosomes and MVs in different diseases. Pioneering work supported the idea that extracellular vesicles carry a cargo of proteins,

Key words: exosome, innate immunity, microvesicle, parasite-host cell interaction, phosphatidylserine.

Abbreviations used: $\left[\mathrm{Ca}^{2+}\right]_{\mathrm{d}}$, intracellular $\mathrm{Ca}^{2+}$ concentration; miRNA, microRNA; $\mathrm{MV}$, microvesicle; PS, phosphatidylserine; TGF $\beta$, transforming growth factor $\beta$.

${ }^{1}$ These authors contributed equally to this paper.

${ }^{2}$ To whom correspondence should be addressed (email marcel.ivan.ramirez@gmail.com). lipids, nucleic acids and metabolites that transform or send a communication signal to other cells or surroundings areas. The second part of the present review, which is our particular interest, contains recent descriptions of extracellular vesicles in diseases caused by protozoan parasites. Our aim is to analyse sensing and responses of cells during the interaction of parasite and host cell.

\section{Exosomes and MVs are released from cells in different ways}

Exosomes and MVs are released from healthy cells via an energy-dependent mechanism, displaying differences in synthesis, size, function and composition [2].

Exosomes are membrane vesicles $(40-100 \mathrm{~nm}$ in diameter) released mainly as physiological activity from secretory pathway of eukaryotic cells [3]. They are formed after inward budding of endosomes in intraluminal vesicles, forming the multivesicular body, and release of exosomes by exocytosis, without signalling apoptotic or necrotic processes [4] (Figure 1). Exosomes contain proteins derived from their cell of origin enriched for histones [5], MHC proteins I and II, heat-shock proteins and other proteins [6].

In contrast with exosomes, MVs are not formed in the endocytic pathway. They are formed from a budding of the plasma membrane, in a $\mathrm{Ca}^{2+}$-dependent mechanism, and their size varies $(100 \mathrm{~nm}-1 \mu \mathrm{m})$. The formation of MVs is an innate property of most cell types occurring in response to activation of a cellular processes [7-9]. Briefly, external stimuli, activators or some kind of cell damage increase $\mathrm{Ca}^{2+}$ influx to the cytoplasm or its release from internal sources. The rise in $\left[\mathrm{Ca}^{2+}\right]_{i}$ (intracellular $\mathrm{Ca}^{2+}$ concentration) is followed by calpain-mediated cleavage of the actin cytoskeleton. In this condition, scramblase is activated and transports the negatively charged phospholipids from the inner to the outer leaflet of plasma membrane [10], resulting in MV formation with PS (phosphatidylserine) exposure (Figure 1). MVs may contain different ratios for phospholipids and bioactive lipids, depending on the 
Figure 1 | Schematic representation of an eukaryotic cell showing the endocytic pathway and multivesicular body origin of exosomes compared with the calpain and scramblase activation mechanism to release MVs from the plasma membrane

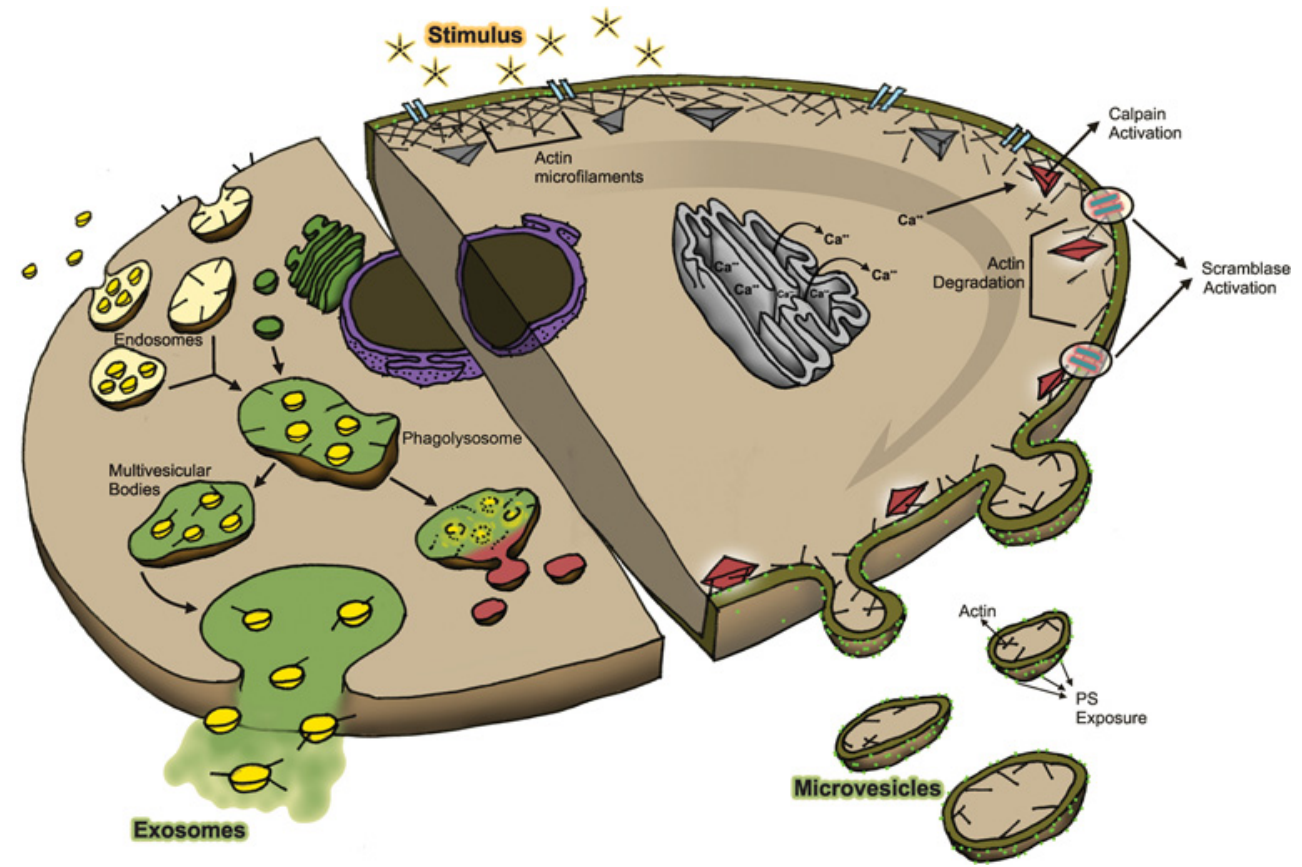

stimulus or cellular origin [6], RNAs [mRNA and miRNAs (microRNAs)] [11], enzymes and cytoskeleton proteins derived from cytoplasm [7]. They also carry cytokines and receptors characteristic of their cellular origin.

\section{MVs originate by induction}

MVs are often associated with cellular responses to activation [10]: chemical, biochemical and mechanical triggers in a natural or artificial way. The processes involving MV formation and release are therefore a cellular response injury that reduces excess $\left[\mathrm{Ca}^{2+}\right]_{i}$, as well as export of damaging agents, allowing the cell to recover. Cells in response to stress produce increased levels of MVs [3] and display different signalling molecules [10]. At times, there is a close relationship between the MVs produced and the stress factor to which cells were subjected [12].

\section{Exosomes and MVs: role in intercellular communication}

Exosomes are implicated in many immunological [9], cellular [5] and metabolic [13] activities. Viral particles evade immune detection, entering cells through exosomes of their host [14]. They deliver mRNA and miRNA to other cells $[15,16]$. Moreover, MVs have been described as communicators, transferring products between distant cells. This would allow the passage of easily degraded or $\mathrm{pH}$-sensitive molecules such as RNAs [15] or particular types of protein [3] and enzymes [5] from the membrane or a small amount of 'protected' cytoplasm [9]. To guarantee the successful communication between MVs and recipient cell, membrane fusion is essential for the delivery of internally transported molecules [17].

MVs drew attention when a dramatic relationship was shown between diseases and MV release from affected tissues $[18,19]$. The most striking feature of MV biology is their ability to transfer carcinogenic factors, being related to the establishment and progression of disease in surrounding tissues. The impact and applicability of MVs in infection detection for difficult cases, even in cancer, are of great scientific interest. The description of exosomes and MVs in parasite and host cell interaction is discussed in the next section.

\section{Dynamic release of extracellular vesicles modifies parasite-host cell interaction}

Protozoans possess plenty of virulence factors and immuneevasion mechanisms to survive host defences and establish infection. Great attention was given to the characterization of key surface molecules and enzymatic activities detected in cellular extracts and supernatants from cultured parasites in vitro. Recently, there has been a growing perception that protozoa release exosomes or MVs to communicate with host cells.

The plasticity of protozoa to release extracellular vesicles has increased interest in analysing the information a cell is sending to another cell and the surrounding medium. The ability to be sensitive to stimuli and respond with release of products that transform host cells (proteins, metabolites 
Table 1 | Extracellular MVs described for parasites

\begin{tabular}{|c|c|c|c|}
\hline Parasite & Named & Described function & Reference \\
\hline \multirow[t]{3}{*}{ Trypanosoma cruzi } & Membrane vesicles & Shedding of surface antigens & {$[20]$} \\
\hline & Membrane vesicles & $\begin{array}{l}\text { Increase extracellular matrix components in } \\
\text { non-infected cells }\end{array}$ & {$[21]$} \\
\hline & Parasite-shed vesicles & $\begin{array}{l}\text { Increase heart pathology in pre-immunized } \\
\text { mice }\end{array}$ & {$[22]$} \\
\hline Trypanosoma cruzi X THP-1 cells & Plasma membrane-derived vesicles & $\begin{array}{l}\text { Protect parasite from complement lysis and } \\
\text { increase infection }\end{array}$ & {$[23]$} \\
\hline Tryponosoma brucei & MV-like bodies & Export of proteins & {$[24]$} \\
\hline \multirow[t]{3}{*}{ Leishmania donovani } & Exosome-like vesicles & Export of proteins & {$[25]$} \\
\hline & Exosomes & Response to environmental changes & {$[26]$} \\
\hline & Exosomes & $\begin{array}{l}\text { Modulate cytokine response from human } \\
\text { monocyte and the phenotype of } \\
\text { monocyte-derived dendritic cells in vitro }\end{array}$ & {$[27]$} \\
\hline Plasmodium falciparum & Platelet microparticles & $\begin{array}{l}\text { Transfer of platelet antigens to the surface of } \\
\text { infected red blood cells }\end{array}$ & {$[28]$} \\
\hline Plasmodium berghei & Parasite-derived plasma microparticles & Activation of macrophages & {$[29]$} \\
\hline Plasmodium vivax & Microparticles & $\begin{array}{l}\text { Increased levels of MVs from platelets were } \\
\text { linked with fever and duration of symptoms }\end{array}$ & {$[30]$} \\
\hline Plasmodium yoelii & Exosomes & $\begin{array}{l}\text { Exosomes derived from infected reticulocytes } \\
\text { protect mice from lethal infection }\end{array}$ & {$[31]$} \\
\hline
\end{tabular}

or RNA) has initiated a new age in the host cell-parasite relationships. What is the participation of these vesicles to the establishment of infection? How are extracellular vesicles from protozoan and surroundings cell related? What is the composition of these vesicles? These are emerging fascinating questions which are currently unanswered.

\section{Exosomes and MVs at the protozoan parasites and host cell interaction}

The production of exosomes or MVs has been described as being spontaneously released by parasites into culture medium, in different models of parasite interaction and in some diseases caused by protozoans (Table 1). In this section, we describe the most relevant findings of the involvement of exosomes and MVs for the non-invasive parasites Trypanosoma brucei and Giardia intestinalis, and for the invasive parasites Trypanosoma cruzi, Leishmania sp. and Plasmodium sp.

\section{Non-invasive parasites Exosomes driving innate immunity}

T. bruce $i$ is an extracellular parasite that is transmitted by tsetse flies and produces a lethal disease called human African trypanosomiasis. Proteins exported by T. brucei are important modulators of the immune response as they were described to inhibit the maturation of dendritic cells and induce lymphocytic allogenic responses. The study of the T. brucei secretome has shown a new secretion pathway in Trypanosoma: the delivery of proteins in vesicles from 50 to
$100 \mathrm{~nm}$ that could regulate innate immunity during parasitic infection [24].

\section{MVs as a response to environmental changes}

$G$. intestinalis is a parasitic protozoan that produces diarrhoeal illness and affects millions worldwide. Giardia has two stages in its life cycle: trophozoite (replicative form) and cyst (infective form). The cyst is ingested by human hosts through contaminated food or water. This stage is resistant to the external environment and when the mammalian host ingests the cyst, the exposure to acid from the stomach causes excystation. Then, cysts release trophozoites at the proximal small intestine. The trophozoites replicate and colonize the upper small intestine, attaching to the epithelial cells. Some trophozoites exposed to biliary fluids stimulate the process of encystation, producing cysts in the jejunum. Then the cysts pass into faeces, completing the transmission cycle after infection of new hosts [32].

The parasite must pass through environments of different osmolarity and $\mathrm{pH}$ during the life cycle and transformations from the cyst to trophozoite. We have hypothesized that $G$. intestinalis trophozoites release MVs to resist changes of $\mathrm{pH}$ during the course of the infection. The ability of trophozoites to release $\mathrm{MVs}$ was investigated under two $\mathrm{pH}$ values, emulating physiological condition in vivo. We have used normal human serum as inductor (5\%) and observed the MV release at $\mathrm{pH} 3.0$ and 8.0 and with a 10-fold higher bile concentration (I. Evans-Osses and M.I. Ramirez, unpublished work). We have seen intense MV formation under different conditions after 5 and $10 \mathrm{~min}$ of incubation (Figure 2A). The MV formation and the 
Figure 2 | MV release by different protozoan parasites

(A) MV release from $G$. intestinalis as environmental sensing. Trophozoites ( $2 \times 10^{7}$ parasites) were incubated with $5 \%$ NHS (normal human serum), at pH 3, at pH 8 or with $10 \times$ bile at $37^{\circ} \mathrm{C}$ for 5 or $10 \mathrm{~min}$. N.I., non-induced. MVs in the supernatant were quantified by flow cytometry. (B) Different strains of $T$. cruzi induce MV release from monocytes in a $\mathrm{Ca}^{2}+$-dependent fashion. T. cruzi $\left(5 \times 10^{6}\right.$, metacyclic or tissue-culture-derived trypomastigotes) were incubated with THP-1 cells $\left(10^{6}\right)$ for $60 \mathrm{~min}$ at $37^{\circ} \mathrm{C}$, with or without EGTA $(5 \mathrm{mM})$. Afterwards, the cell supernatant was analysed for MV quantification by flow cytometry ("P<0.01; $" P<0.05)$.

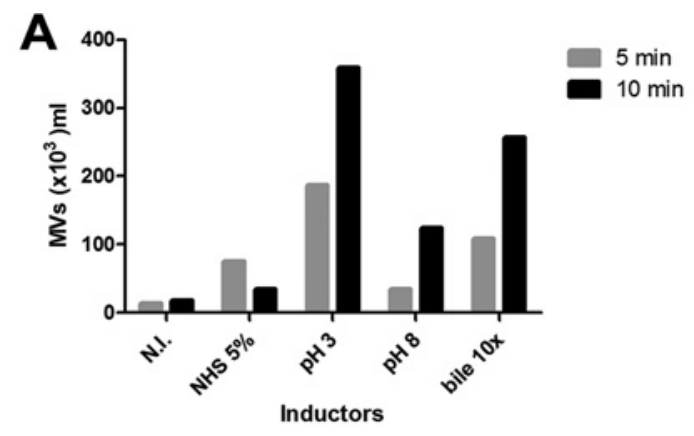

B
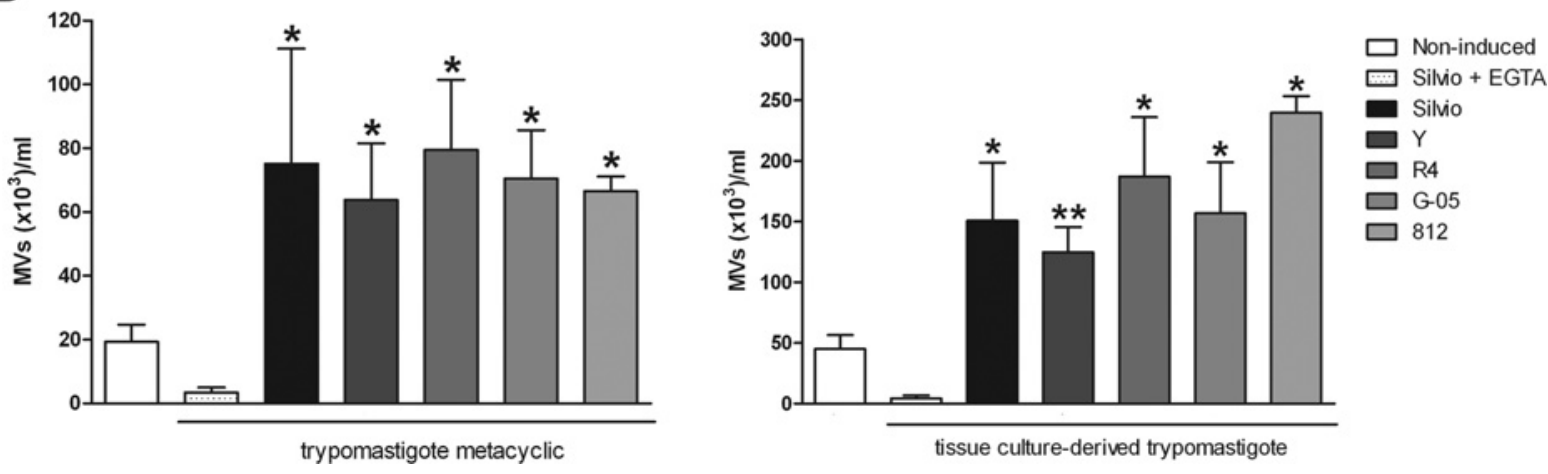

physiological role of this active vesiculation are under investigation.

\section{Invasive parasites}

\section{Exosomes as a response to environmental changes}

Leishmania is a trypanosomatid parasite that has tropism to macrophages and survives inside an acidic parasitophorous vacuole. In this parasite-host cell relationship, Leishmania subverts the killing response to persist with the infection as well as the host to provide nutrients for parasite survival. Silverman et al. [25] described the release of exosome-like vesicles by promastigotes of Leishmania donovani in the conditioned medium. Afterwards, they demonstrated that intracellular amastigotes also release exosomes inside the parasitophorous vacuole as a sensor of elevated temperature and low pH [26]. Exosomes are delivered to the cytoplasm of infected macrophage, as a response to the environmental changes between the insect midgut and the acidic vacuole in vertebrate macrophages [26]. Moreover, the authors demonstrated that exosomes delivered from Leishmania have an immunosuppressive effect on host cells. They modulate the cytokine production by human monocytes and the phenotype of MoDCs (monocyte-derived dendritic cells) in vitro [27]. These effects exacerbate Leishmania disease progression and involve exosomes in the regulation of cytokine production with anti-inflammatory effects.

\section{Exosomes and MVs related with infection from different species of Plasmodium}

Cerebral malaria is the most severe and mortal complication of Plasmodium falciparum infection. MVs from activated platelets transfer platelet antigen to the surface of infected red blood cells with an increase in their cytoadherence to endothelial cells in brain microvessels [33]. The proinflammatory process increases the activation of monocytes, platelets and MVs in the circulation, obstructing vessels, leading to hypoxia or ischaemia and affecting the blood-brain barrier, with eventual damage to the brain parenchyma. This cerebral malaria was reviewed by Coltel et al. [34].

MVs are implicated with inflammation during Plasmodium berghei infection by inducing a potent activation of macrophages [29]. It has been shown that platelet-, erythrocyte- and leucocyte-derived plasma membrane vesicles are increased during acute Plasmodium vivax malaria infection [30]. Moreover, increased levels of MVs derived from platelets were linked with fever and duration of symptoms. 
Exosomes from Plasmodium were described to modulate immune response. Exosomes purified from Plasmodium yoelii-infected reticulocytes protect mice from lethal infections [31]. Taken together, these data open up new strategies to control the Plasmodium infection and understand the role of exosome and MV release during this pathogenesis.

\section{T. cruzi and host cells use MVs as a novel mechanism of communication}

T. cruzi is the aetiological agent of American trypanosomiasis, highly prevalent in South and Central America. T. cruzi has a complex life cycle that alternates between an insect vector and a vertebrate host. The parasite has to evade the innate immune system and infect host cells to progress in the life cycle [35]. Parasitism is eventually controlled by several immune mechanisms: complement-mediated lysis, cytokine-activated macrophages, opsonization by antibody and T-cellmediated cytotoxicity.

MV release by T. cruzi was first described in tissue-culturederived trypomastigotes, as a mechanism of spontaneously shedding of surface antigens into the culture medium [20]. It was described antigens from 70 to $150 \mathrm{kDa}$ in vesicles that range from 20 to $80 \mathrm{~nm}$ [36-38]. The role of vesicles released spontaneously was observed when they can be adsorbed to non-infected mammalian cell membranes, increasing the expression of extracellular matrix components [21]. Preimmunization of mice using trypomastigote vesicles induce severe heart pathology with intense inflammatory reaction and higher number of amastigote nests in cardiac tissue [22].

We have described different mechanisms that metacyclic trypomastigote forms of $T$. cruzi use for evasion of complement-mediated lysis [39-40]. Recently, we have observed that the parasite induces the release of MVs from blood cells early in infection, in a $\mathrm{Ca}^{2+}$-dependent process [23], which present actin and surface-exposed PS, two hallmark characteristics of MVs. After MV release, these vesicles form a complex with $\mathrm{C} 3$ convertase on the parasite surface, stabilizing the enzyme and inhibiting its activity, protecting parasites from complement lysis and increasing parasite survival [23]. MVs were detected in plasma of infected mice even after 8 days of metacyclic infection. These vesicles also carry TGF $\beta$ (transforming growth factor $\beta$ ), which promote the parasite invasion in the course of infection in vivo and in vitro [23].

Different strains of T. cruzi induce MV release during the contact of parasite with blood cells (P. Deolindo, I.C. De Almeida, I.J. Messias-Reason and M.I. Ramirez, unpublished work). Besides differences in molecules observed on metacyclic trypomastigote or tissue-culture-derived trypomastigote surfaces, both stages of parasite can induce MV release after interaction with monocytes, in a $\mathrm{Ca}^{2+}$-dependent manner (Figure 2B).

The induction of MVs by infective stages of $T$. cruzi emphasized the role that these membrane vesicles have in parasite survival strategy and in cell-cell communication. Experiments performed using lipophilic dyes showed that MVs can be formed on the parasite and the monocyte membrane during the interaction of these cells. Fusion events of both vesicles can be important in communication between parasite and host cell (P. Deolindo, I.C. De Almeida, I.J. Messias-Reason and M.I. Ramirez, unpublished work). Antigen-containing vesicles could be internalized by other cells, processed and presented in the context of MHC, eliciting an anti-parasite immune response and could be involved in immunopathogenesis.

\section{Conclusions}

Extracellular vesicles represent a new area of cellular biology in which the biogenesis, biochemical content, transport in the cells and signal transduction are under investigation. Despite the extensive description in cell communication and tumour progression in cancer, its role in parasite infectivity and development of infection is still poorly understood. Exosomes and MVs associated with parasitic infections need to be better understood. The use as diagnostic markers for diseases, or as vaccines, depends on the increased knowledge about their content, the continuing presence in the blood and the capacity to be recognized by cells involved in disease development.

It is the beginning of a new world of relationships between parasite and host cells, where extracellular vesicles are characters in a language that we must try to decipher.

\section{Acknowledgements}

We thank the Biochemical Society and London Metropolitan University for organizing the Microvesiculation and Disease conference. We also thank Bruno Marques for helping with Figure 1.

\section{Funding}

This work is supported from Coordenação de Aperfeiçoamento de Pessoal de Nível Superior (CAPES) 'Programa de Parasitologia Básico', Conselho Nacional de Desenvolvimento Científico e Tecnológico (CNPq) and Fiocruz. P.D. is a visiting fellow from CNPq, I.E.-O. is a postdoc from CAPES and M.I.R. is a CNPq fellow.

\section{References}

1 Chargaff, E. and West, R. (1946) The biological significance of the thromboplastic protein of blood. J. Biol. Chem. 166, 189-197

2 Rak, J. (2010) Microparticles in cancer. Semin. Thromb. Hemostasis 36 $888-906$

3 Pizzirani, C., Ferrari, D., Chiozzi, P., Adinolfi, E., Sandona, D., Savaglio, E. and Di Virgilio, F. (2007) Stimulation of P2 receptors causes release of IL- $1 \beta$-loaded microvesicles from human dendritic cells. Blood $\mathbf{1 0 9}$ 3856-3864

4 Muralidharan-Chari, V., Clancy, J.W., Sedgwick, A. and D'Souza-Schorey, C. (2010) Microvesicles: mediators of extracellular communication during cancer progression. J. Cell Sci. 123, 1603-1611

5 Kesimer, M., Scull, M., Brighton, B., DeMaria, G., Burns, K., O’Neal, W. Pickles, R.J. and Sheehan, J.K. (2009) Characterization of exosome-like vesicles released from human tracheobronchial ciliated epithelium: a possible role in innate defense. FASEB J. 23, 1858-1868 
6 Aoki, N., Jin-no, S., Nakagawa, Y., Asai, N., Arakawa, E., Tamura, N., Tamura, T. and Matsuda, T. (2007) Adipocyte-derived microvesicles are associated with multiple angiogenic factors and induce angiogenesis in vivo and in vitro. Endocrinology 151, 2567-2576

7 Fox, J.E., Austin, C.D., Boyles, J.K. and Steffen, P.K. (1990) Role of the membrane skeleton in preventing the shedding of procoagulant-rich microvesicles from the platelet plasma membrane. J. Cell Biol. 111, 483-493

8 Hugel, B., Martinez, M.C., Kunzelmann, C. and Freyssinet, J.M. (2005) Membrane microparticles: two sides of the coin. Physiology 20, 22-27

9 Nolan, S., Dixon, R., Norman, K., Hellewell, P. and Ridger, V. (2008) Nitric oxide regulates neutrophil migration through microparticle formation. Am. J. Pathol. 172, 265-273

10 Angelot, F., Seillès, E., Biichlé, S., Berda, Y., Gaugler, B., Plumas, J., Chaperot, L., Dignat-George, F., Tiberghien, P., Saas, P. and Garnache-Ottou, F. (2009) Endothelial cell-derived microparticles induce plasmacytoid dendritic cell maturation: potential implications in inflammatory diseases. Haematologica 94, 1502-1512

11 Deregibus, M.C., Cantaluppi, V., Calogero, R., Lo lacono, M., Tetta, C., Biancone, L., Bruno, S., Bussolati, B. and Camussi, G. (2007) Endothelial progenitor cell derived microvesicles activate an angiogenic program in endothelial cells by a horizontal transfer of mRNA. Blood $\mathbf{1 1 0}$ 2440-2448

12 Agouni, A., Mostefai, H.A., Porro, C., Carusio, N., Favre, J., Richard, V., Henrion, D., Martinez, M.C. and Andriantsitohaina, R. (2007) Sonic hedgehog carried by microparticles corrects endothelial injury through nitric oxide release. FASEB J. 21, 2735-2741

13 Putz, U., Howitt, J., Lackovic, J., Foot, N., Kumar, S., Silke, J. and Tan, S.S. (2008) Nedd 4 family-interacting protein 1 (Ndfip1) is required for the exosomal secretion of Nedd4 family proteins. J. Biol. Chem. 283 32621-32627

14 Gould, S.J., Booth, A.M. and Hildreth, J.E. (2003) The Trojan exosome hypothesis. Proc. Natl. Acad. Sci. U.S.A. 100, 10592-10597

15 Quesenberry, P.J. and Aliotta, J.M. (2010) Cellular phenotype switching and microvesicles. Adv. Drug Delivery Rev. 62, 1141-1148

16 Robertson, C., Booth, S.A., Beniac, D.R., Coulthart, M.B., Booth, T.F. and McNicol, A. (2006) Cellular prion protein is released on exosomes from activated platelets. Blood 107, 3907-3911

17 Szajnik, M., Czystowska, M., Szczepanski, M.J., Mandapathil, M. and Whiteside, T.L. (2010) Tumor-derived microvesicles induce, expand and up-regulate biological activities of human regulatory T cells (Treg). PLoS ONE 5, e11469

18 Antwi-Baffour, S., Kholia, S., Aryee, Y.K., Ansa-Addo, E.A., Stratton, D., Lange, S. and Inal, J.M. (2010) Human plasma membrane-derived vesicles inhibit the phagocytosis of apoptotic cells: possible role in SLE. Biochem. Biophys. Res. Commun. 398, 278-283

19 Hind, E., Heugh, S., Ansa-Addo, E.A., Antwi-Baffour, S., Lange, S. and Inal, J. (2010) Red cell PMVs, plasma membrane-derived vesicles calling out for standards. Biochem. Biophys. Res. Commun. 399, 465-469

20 Goncalves, M.F., Umezawa, E.S., Katzin, A.M., de Souza, W., Alves, M.J., Zingales, B. and Colli, W. (1991) Tryponosomo cruzi: shedding of surface antigens as membrane vesicles. Exp. Parasitol. 72, 43-53

21 Pinho, R.T., Vannier-Santos, M.A., Alves, C.R., Marino, A.P., Castello Branco, L.R. and Lannes-Vieira, J. (2002) Effect of Tryponosomo cruzi released antigens binding to non-infected cells on anti-parasite antibody recognition and expression of extracellular matrix components. Acta Trop. 83, 103-115

22 Torrecilhas, A.C.T., Tonelli, R.R., Pavanelli, W.R., da Silva, J.S., Schumacher, R.I., de Souza, W., Cunha e Silva, N., de Almeida Abrahamsohn, I., Colli, W. and Alves, M.J.M. (2009) Tryponosomo cruzi: parasite shed vesicles increase heart parasitism and generate an intense inflammatory response. Microbes Infect. 11, 29-39

23 Cestari, I., Ansa-Addo, E., Deolindo, P., Inal, J.M. and Ramirez, M.I. (2012) Trypanosoma cruzi immune evasion mediated by host cell-derived microvesicles. J. Immunol. 188, 1942-1952
24 Geiger, A., Hirtz, C., Bécue, T., Bellard, E., Centeno, D., Gargani, D. Rossignol, M., Cuny, G. and Peltier, J.B. (2010) Exocytosis and protein secretion in Trypanosoma. BMC Microbiol. 10, 20

25 Silverman, J.M., Chan, S.K., Robinson, D.P., Dwyer, D.M., Nandan, D., Foster, L.J. and Reiner, N.E. (2008) Proteomic analysis of the secretome of Leishmanio donovani. Genome Biol. 9, R35

26 Silverman, J.M., Clos, J., de'Oliveira, C.C., Shirvani, O., Fang, Y., Wang, C. Foster, L.J. and Reiner, N.E. (2010) An exosome-based secretion pathway is responsible for protein export from Leishmonio and communication with macrophages. J. Cell Sci. 123, 842-852

27 Silverman, J.M., Clos, J., Horakova, E., Wang, A.Y., Wiesgigl, M., Kelly, I., Lynn, M.A., McMaster, W.R., Foster, L.J., Levings, M.K. and Reiner, N.E. (2010) Leishmonia exosomes modulate innate and adaptive immune responses through effects on monocytes and dendritic cells. J. Immunol. 185, 5011-5022

28 Faille, D., El-Assaad, F., Alessi, M.C., Fusai, T., Combes, V. and Grau, G.E. (2009) Platelet-endothelial cell interactions in cerebral malaria: the end of a cordial understanding. Thromb. Haemostasis 102, 1093-1102

29 Couper, K.N., Barnes, T., Hafalla, J.C., Combes, V., Ryffel, B., Secher, T., Grau, G.E., Riley, E.M. and de Souza, J.B. (2010) Parasite-derived plasma microparticles contribute significantly to malaria infection-induced inflammation through potent macrophage stimulation. PLoS Pathog. $\mathbf{6}$, e1000744

30 Campos, F.M., Franklin, B.S., Teixeira-Carvalho, A., Filho, A.L., de Paula, S.C., Fontes, C.J., Brito, C.F. and Carvalho, L.H. (2010) Augmented plasma microparticles during acute Plasmodium vivax infection. Malar. J. 9, 327

31 Martin-Jaular, L., Nakayasu, E.S., Ferrer, M., Almeida, I.C. and Del Portillo, H.A. (2011) Exosomes from Plasmodium yoelii-infected reticulocytes protect mice from lethal infections. PLoS ONE 6, e26588

32 Adam, R.D. (2001) Biology of Giardia lamblio. Clin. Microbiol. Rev. 14 447-475

33 Combes, V., Rosenkranz, A.R., Redard, M., Pizzolato, G., Lepidi, H., Vestweber, D., Mayadas, T.N. and Grau, G.E. (2004) Pathogenic role of P-selectin in experimental cerebral malaria: importance of the endothelial compartment. Am. J. Pathol. 164, 781-786

34 Coltel, N., Combes, V., Wassmer, S.C., Chimini, G. and Grau, G.E. (2006) cell vesiculation and immunopathology: implications in cerebral malaria. Microbes Infect. 8, 2305-2316

35 Lambris, J.D., Ricklin, D. and Geisbrecht, B.V. (2008) Complement evasion by human pathogens. Nat. Rev. Microbiol. 6, 132-142

36 Almeida, I.C., Ferguson, M.A., Schenkman, S. and Travassos, L.R. (1994) Lytic anti- $\alpha$-galactosyl antibodies from patients with chronic Chagas' disease recognize novel 0 -linked oligosaccharides on mucin-like glycosyl-phosphatidylinositol-anchored glycoproteins of Trypanosomo cruzi. Biochem. J. 304, 793-802

37 Acosta-Serrano, A., Almeida, I.C., Freitas-Junior, L.H., Yoshida, N. and Schenkman, S. (2001) The mucin-like glycoprotein super-family of Tryponosoma cruzi: structure and biological roles. Mol. Biochem. Parasitol. 114, 143-150

38 Schenkman, S., Eichinger, D., Pereira, M.E. and Nussenzweig, V. (1994) Structural and functional properties of Tryponosomo trans-sialidase. Annu. Rev. Microbiol. 48, 499-523

39 Cestari, I.S., Evans-Osses, I., Freitas, J.C., Inal, J.M. and Ramirez, M.I. (2008) Complement C2 receptor inhibitor trispanning confers an increased ability to resist complement-mediated lysis in Trypanosomo cruzi. J. Infect. Dis. 198, 1276-1283

40 Cestari, I. and Ramirez, M.I. (2010) Inefficient complement system clearance of Tryponosomo cruzi metacyclic trypomastigotes enables resistant strains to invade eukaryotic cells. PLoS ONE 5, e9721

Received 29 August 2012

doi:10.1042/BST20120217 